\title{
A Normalization Method of Distorted Korean SMS Sentences for Spam Message Filtering
}

\author{
Kang Seung-Shik ${ }^{+}$
}

\begin{abstract}
Short message service(SMS) in a mobile communication environment is a very convenient method. However, it caused a serious side effect of generating spam messages for advertisement. Those who send spam messages distort or deform SMS sentences to avoid the messages being filtered by automatic filtering system. In order to increase the performance of spam filtering system, we need to recover the distorted sentences into normal sentences. This paper proposes a method of normalizing the various types of distorted sentence and extracting keywords through automatic word spacing and compound noun decomposition.
\end{abstract}

Keywords : Spam Message, SMS Filtering, Sentence Normalization, Automatic Word Spacing, Keyword Extraction

\section{스팸 문자 필터링을 위한 변형된 한글 $\mathrm{SMS}$ 문장의 정규화 기법}

$$
\text { 강 승 식 }{ }^{\dagger}
$$

요 약

\begin{abstract}
휴대폰에서 문자 메시지 전송 기능은 현대인들에게 매우 편리한 새로운 형태의 의사소통 방식이다. 반면에 문자 메시지 기능을 악용한 광고성 문자들이 너무 많이 쏟아져서 휴대폰 사용자들은 스팸 문자 공해에 시달리는 심각한 부작용을 낳게 되었다. 광고성 문자를 발송하 는 사람들은 문자 메시지가 자동으로 차단되는 것을 회피하기 위해 한글 문장을 다양한 형태로 변형하거나 왜곡시키고 있으며, 이러한 문 자 메시지를 자동으로 차단하기 위해서는 변형되거나 왜곡된 문장들을 정상적인 한글 문장으로 정규화하는 기술이 필수적이다. 본 논문에 서는 변형되거나 왜곡된 광고성 문자 메시지를 정상적인 문장으로 정규화하고 정규화된 문장으로부터 자동 띄어쓰기 및 복합명사 분해 과 정을 거쳐 키워드를 추출하기 위한 방법을 제안하였다.
\end{abstract}

키워드 : 스팸 문자, SMS 필터링, 문장 정규화, 자동 띄어쓰기, 키워드 추출

\section{1. 서 론}

휴대폰으로 문자를 주고받는 SMS 메시지 전송 기능은 현대인들에게 새로운 형태의 의사소통 방식을 제공하고 있 다. 그럼으로써 모바일 환경에서 새로운 문화를 만들어 내 기도 하고 현대 생활을 영위하는 데 매우 편리한 수단으로 자리를 잡고 있다[1]. 이러한 편의성이 있는 반면에 휴대폰 의 문자 메시지 기능을 악용하여 광고성 문자들을 불특정 다수에게 보내는 일이 도를 지나치는 일들이 발생하고 있으 며, 휴대폰 사용자들은 스팸 문자의 공해에 시달리는 부작 용이 사회적인 문제로 등장하게 되었다[2].

\footnotetext{
† 종신회원 : 국민대학교 컴퓨터공학부 교수

Manuscript Received: March 19, 2014

First Revision: June 20, 2014

Accepted: June 21, 2014

* Corresponding Author: Kang Seung-Shik(sskang@kookmin.ac.kr)
}

스팸 메일과 스팸 문자, 뉴스 기사 및 블로그 등에 대한 광고성 댓글은 수많은 사람들에게 피해를 주고 있으며 이로 인해 지불해야 하는 사회적 비용은 매우 크다[3]. 스팸 메일 을 차단하는 연구는 이미 심도있게 진행되어 왔고 자동으로 스팸 메일을 차단 시스템이 개발되어 메일 서버는 스팸 메 일로 분류된 메일들을 별도로 관리를 하고 있다[4,5,6]. 스팸 메일과 정상적인 메일을 구분하는 방법으로는 문서 분류 기 법을 이용한다. 스팸 메일 인식 시스템은 모든 이메일들을 두 개의 범주로 구분하는 문제이기 때문이다. 따라서 스팸 메일을 인식하는 기법으로는 SVM, Naive Bayse, 최대 엔트 로피 등 일반적인 기계 학습 이론을 이용하고 있다[7,8,9].

스팸 메일은 여러 문장으로 구성되는 문서를 스팸 문서와 스팸이 아닌 정상적인 문서로 분류하는데 비해 휴대폰에서 스팸 문자 메시지는 한두 문장으로 구성되는 짧은 문서이 
다. 이는 문자 메시지의 특성상 통상적으로 80바이트(한글 40 음절) 이내의 짧은 문장으로 구성되기 때문이다. 또한, 광고성 스팸 문자를 작성하는 사람들은 스팸으로 자동 차단 되는 것을 피하기 위해 불필요한 기호들을 추가하거나 문자 를 변형, 왜곡시키는 기법을 사용한다. 따라서 스팸 문자인 지를 자동으로 판단하는 것은 스팸 메일 분류 시스템보다 어려운 문제이다. 스팸 문자 메시지의 예는 아래와 같다.

- 카@드@결@제,연@체@자금때문머리아프시죠, 저희가 결제해드립니다,전화주세요.

- 귀빈을[카_지]노 *특별회원 으로* 모십니다 [현금3만 원]드림 www.tuu33.com

>df8282.(Com 국_내\&최고>카지 l 노<설\&명절/이벤트 당첨/2만>회원가입후고객센터

- 병원처방 20 정/곽 32 정/할인행사/후불/전문상담!정 $\mathrm{K}$ 품! 비 $\mathrm{K}$ 아 시 $\mathrm{K}$ 알문의는문자예약!

본 연구는 휴대폰에서 대량으로 발송되는 광고성 스팸 문 자를 차단하기 위하여 문자 메시지의 내용을 분석함으로써 왜곡되거나 변형된 한글 문장을 정상적인 문장으로 복원하 는 시스템을 설계하고 구현하는 방법에 관한 것이다. 이 연 구에서 변형된 한글 문장을 복원하기 위하여 한글 자모와 유사한 문자를 한글로 변환하거나, 한글 자모로 구성된 문 자열을 음절로 결합하는 방법을 적용한다.

\section{SMS 문장 정규화의 필요성}

한글 SMS 문장은 여러 가지 유형의 자모 변형 및 음절 변형, 축약 등이 포함되어 있어서 각 변형 유형에 따라 변 형된 부분을 복원하는 과정이 필요하다. 또한, 광고성 SMS 문장의 특징은 띄어쓰기를 무시하거나 불필요한 기호를 삽 입하기 때문에 불필요한 기호를 제거하고 자동으로 어절을 구분해 주는 과정을 거쳐서 SMS 문장에서 주요 키워드를 추출해 주어야 한다.

위 예제는 실제 문자 메시지에서 다양한 형태로 표현되는 어휘들의 실제 예제의 일부이다. 이 데이터를 살펴보면, '대 출'이라는 어휘가 스팸 어휘로 등록되어 차단되는 것을 회 피하기 위하여 '대'와 '출' 사이에 다양한 특수 기호들을 삽 입하는 방법을 사용하고 있다. 그 이유는 특수 기호를 삽입 하더라도 의미를 전달하는 데 아무런 문제가 없기 때문이 다. 그런데 특수 기호를 삽입하는 방식은 단순히 기호만 제
거하면 해당 문구를 차단할 수가 있기 때문에 스팸 어휘로 차단되는 것을 피하기 위한 다양한 방법들이 고안되었고 '대'와 같이 자모를 분리한다든지, ‘ㄷ $\mathrm{H}$ 리'와 같이 분리된 자모를 유사한 형태의 영문자, 숫자로 대치하여 스팸으로 차단되지 않도록 하는 교묘한 방법들이 사용되고 있다.

또한, 문자 메시지는 한글 띄어쓰기 규칙을 지키지 않을 뿐만 아니라 스팸 메시지의 경우에 “대 리 운 전”과 같이 고의로 공백들을 삽입하거나 “대.리.운.전”의 예처럼 각 문자 들 사이에 문장부호 등 특수문자를 삽입하는 형태로 왜곡하 기도 한다. 이와 같이 자모를 분리하거나 유사한 문자로 대 치하는 방법에 의하여 하나의 어휘에 대해 매우 다양한 형 태의 변형된 문자열 조합이 가능하다. 따라서 이러한 모든 조합의 변형된 문자열을 차단 어휘집에 수록하는 것은 불가 능하며, 변형된 문자열을 정규화함으로써 정규화된 어휘가 차단 어휘집에 등록되어 있으면 모든 변형된 문자열을 차단 할 수 있도록 할 필요가 있다.

본 연구에서 한국어 문장 복원 시스템은 단순히 문자열 일치 방식에 의해 “대리운전"이 포함된 문자 메시지가 스팸 문자로 차단되는 것을 피하기 위해 “(ㄷ)H리우넌ㄱㄱㄱ 같이 다양한 형태로 단어를 변형하더라도 '대리운전'으로 문 장을 복원해 줌으로써 매우 다양한 형태로 변형된 문자열들 을 모두 차단 문구로 등록하지 않더라도 해당 문자열이 포 함된 문자메시지가 스팸 문자로 차단될 수 있도록 하기 위 한 것이다.

\section{SMS 문장의 정규화 및 키워드 추출}

\section{1 전처리 및 문자 변환}

그림 1은 SMS 문자열 입력으로부터 어휘 정규화 과정 을 거쳐 키워드를 추출하는 과정을 기술한 것이다. 전처리 과정은 공백 문자, 특수 기호 등 스팸 차단에 불필요한 기 호들을 제거하는 것이고, 2 바이트 기호 변환은 괄호 문자, 원 문자 등 2 바이트 기호들 중에서 한글 자모를 대치하여 사용한 기호를 해당 한글 자모로 변환하는 과정이다. 영문 자/숫자 변환은 영문자 중에서 $\mathrm{h} / \mathrm{H}$ 와 같이 모음 ' $\mathrm{H}$ '로 대 치될 수 있는 것, ' $\mathrm{i} / \mathrm{I}$ '와 같이 모음 ' I'로 대치될 수 있는 것 등을 한글 자모로 변환하는 과정이다. 기호 변환 과정 이 끝나면 자모로 분해되어 있는 단어를 음절로 조합한다. 정규화된 문장은 공백이 무시되었으므로 자동 띄어쓰기 모 듈을 적용한 후에 복합명사 분해 과정을 거쳐서 키워드가 추출된다. 


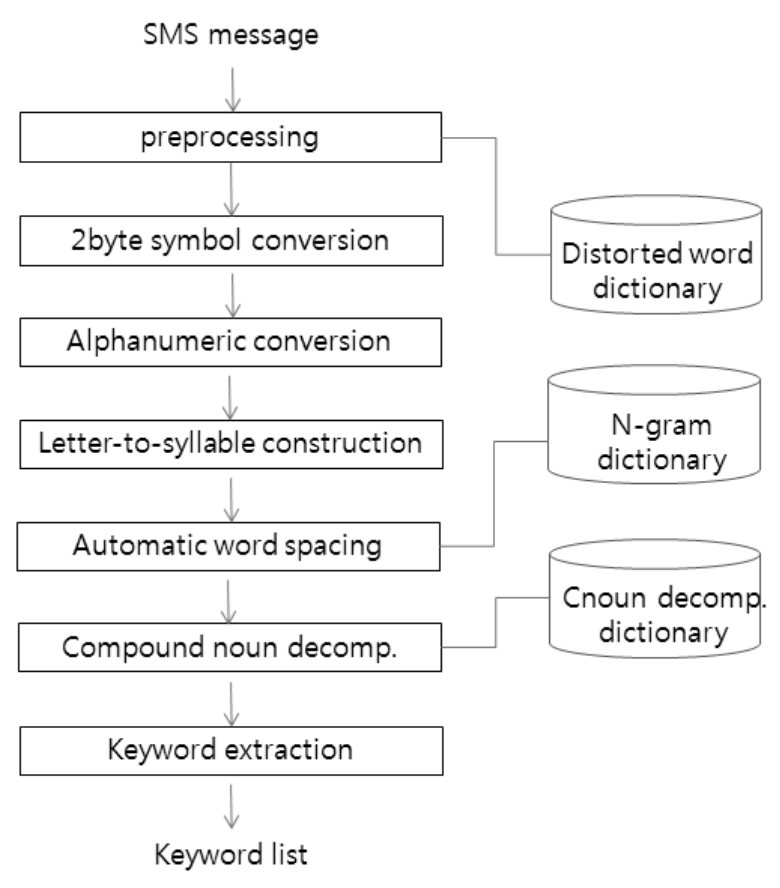

Fig. 1. Keyword extraction by normalization

$3.2 \mathrm{SMS}$ 문장의 문구 보정

$\mathrm{SMS}$ 문장을 복원하는 첫 번째 단계는 생략 또는 통상적 으로 사용되는 변형 문구를 복원하는 것이다. 예를 들어, '캐 피탈'을 '키피탈'이라고 모음 ' $H$ '를 누락시킴으로써 '캐피탈' 이라는 키워드에 의해 문자 메시지가 차단되는 것을 회피하 려고 한다. 다른 예로는 '거부080'을 '거080', ‘x080'과 같이 표현하여 '거부'라는 키워드로 필터링 되지 않도록 하는 경 우이다. 이러한 변형 문구들은 사전에 등록하여 변형 문자 열 사전에 등록된 문자열을 복원한다.

변형 문자열 사전을 참조하여 입력 문자열을 복원한 후

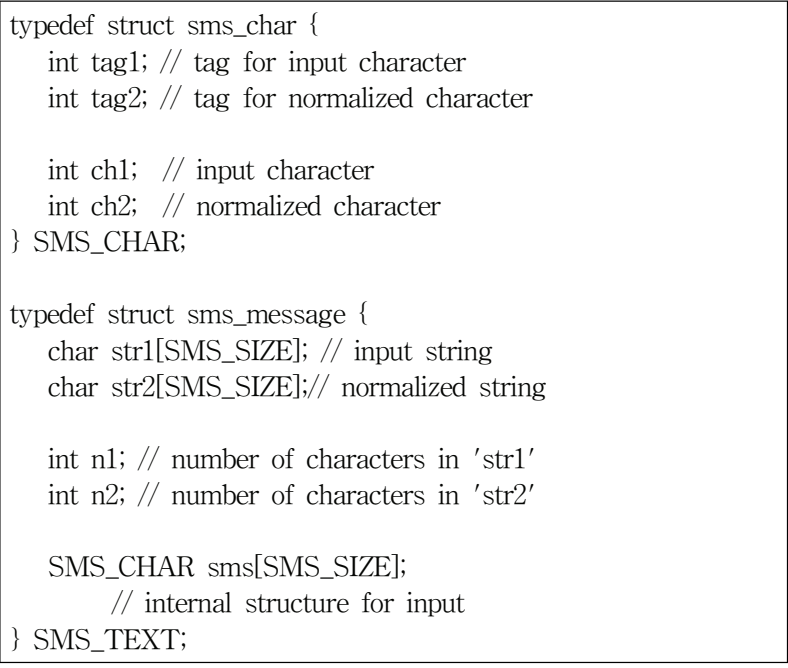

Fig. 2. Data structure for SMS string normalization
문자열 복원을 위한 다음 단계를 시작하기 전에 입력 문자 열을 16 비트 정수 형태로 문자열을 초기화한다. 그 이유는 한글 SMS 문자열이 문자 코드집합에 따라 아스키 코드는 1 바이트, 한글/한자는 2 바이트로 저장되어 문자열 조작하는 데 불편한 점들이 있기 때문이다. 그림 2의 구조체는 $\mathrm{SMS}$ 문자열 보정을 위한 입력 문자열과 보정된 문자열, 그리고 내부적으로 16 비트 정수로 표현하는 데 필요한 자료구조이 다. 구조체 SMS_TEXT의 'str1'은 입력 문자열이고, 'str2'는 최종적으로 문구 보정이 완료된 문자열을 저장하기 위한 것 이다. SMS 문자열을 내부적인 표현인 SMS_CHAR sms[] 에 저장하는 것은 여러 단계에서 문자열 보정을 하는 과정 에서 문구 보정 처리의 편의성을 위한 것이다. 구조체 SMS_CHAR는 각 문자에 대해 입력 문자와 보정된 문자를 16 비트 정수형으로 저장하여 입력 문자와 보정된 문자를 $1: 1$ 로 매핑이 되도록 한다. 또한, 입력 문자 및 보정된 문자 의 유형을 각각 $\operatorname{tag} 1, \operatorname{tag} 2$ 에 표시함으로써 핵심어를 추출하 는데 활용하고자 한다.

다음 단계는 여러 가지 형태로 변형된 문자들을 정상적인 한글로 보정하는 단계이다. 변형된 문자들은 한글 자음 또 는 모음과 유사한 2 바이트 기호, 영문자, 숫자 등으로 표현 된다. 예를 들어, 자음 ' $\mathrm{O}$ ’을 ' $@ / 0 / 0 / 0 /(0)$ ’으로 대치하거나 모음 'H'를 ' $\mathrm{h} / \mathrm{H}$ ', 모음 ' I'를 ' $\mathrm{i} / \mathrm{I} / \mathrm{l} / \mathrm{l}$ '로 대치하는 경우가 많 다. 또한, 발음이 영문자와 유사한 음절 '비'는 'b/B', '지'는 ' $\mathrm{g} / \mathrm{G}$ '로 대치하기도 한다.

\section{3 자동 띄어쓰기에 의한 키워드 추출}

본 연구에서 구현한 문자 메시지 보정 시스템을 이용하여 단계별로 문구가 보정되는 과정을 구체적으로 살펴보면 다 음과 같다. SMS 문자 메시지는 초성, 중성, 종성을 모두 분 리하는 경우도 있지만 '코르'과 같이 종성만 분리하거나 또 는 복합모음 '과'를 '오'로 분해하는 언어 파괴 현상들이 발견되며 ‘왕'의 경우에 ‘왕' 또는 '오 응'으로 변형시키기 도 한다. 본 논문에서는 다양한 형태의 문구 변형 및 한글 을 왜곡한 유형들에 대하여 정상적인 한글 문장으로 복원을 한다. 문구가 보정되면 불필요한 기호들을 제거한 후에 자 동 띄어쓰기, 복합명사 분해 과정을 거쳐 최종으로 키워드 를 추출한다.

- SMS 입력 문장 예제

(o) k (ㅁ) 토/대리 카드,서B스서 $\beta$ 스보다저.렴한 $0 \mathrm{i}$ 율

- 문자 보정 결과

야마토/대리카드,서비스서비스보다저.렴한이율 
- 기호 제거 및 자동 띄어쓰기

야마토대리 카드 서비스 서비스보다 저렴한 이율

SMS 문장을 살펴보면 한글 문장이 음절뿐만 아니라, 자 음, 모음, 영문자, 숫자, 특수기호가 포함된 다양한 유형의 문자들로 구성되는 것을 알 수 있다. 자음과 모음이 분리되 고 유사한 문자로 대치되어 있는 변형된 문장을 정규화하기 위하여 각 문자들에 대해 유형을 구분하는 태그를 정의하는 데 정의된 태그 유형들은 문자 변환 및 음절 구성의 편의성 을 목적으로 정의된다.

음절: $\mathrm{K}$, 자음: $\mathrm{L}$, 모음: $\mathrm{M}$, 한자: $\mathrm{N}$, 기호: $\mathrm{O}$

영문: $\mathrm{A}$, 숫자: $\mathrm{B}$, 문장부호: $\mathrm{C}$, 태그없음:

이와 같이 입력 문자들에 대해 태그를 부착한 이유는 한 글 음절과 자모가 분리된 문자들을 구분함으로써 정상적인 한글 음절인지, 자모 변환과 음절 조합 등 문구 보정이 필 요한 문자인지 판단하기 위한 것이다. 입력 문장에 대한 태 그열과 문구가 보정된 문자열에 대한 태그열을 구성해 보면 다음과 같다.

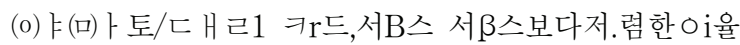

\section{OMOMKCLMLB LAKCKAK KOKKKKCKKLAK}

\section{야마토/대리 카드,서비스 서비스보다저.렴한이율}

\section{K_K_KCK_K_K_KCKKK KKKKKKCKKK_K}

휴대폰의 SMS 문자 메시지에서는 띄어쓰기를 무시하는 경우가 매우 빈번하게 발생한다. 그 이유는 초기에 문자 메 시지의 요금 부과 기준이 80자 단위로 구분되었던 문자 메 시지 사용 환경과도 밀접한 연관이 있다. 따라서 스팸 문자 인식 시스템은 한글 문장의 변형뿐만 아니라 띄어쓰기가 무 시되는 현상이 복합되어 있다. 띄어쓰기를 하지 않은 문장 들은 스팸 문자 차단 시스템의 성능을 저하시키게 되므로 이에 적합한 자동 띄어쓰기 모듈을 적용한다[10]. 그림 3은 문구 보정된 결과에 대해 자동 띄어쓰기를 위해 사용되는 자료구조이다.

자동 띄어쓰기를 적용하더라도 대부분의 문자 메시지들이 조사, 어미가 생략된 채 명사들만 나열하는 경우가 일반적 이다. 자동 띄어쓰기는 띄붙 오류보다 붙띄 오류가 유해성 이 높기 때문에 붙띄 오류를 최소화하기 위하여 가급적 공 백 삽입을 보수적으로 하는 것이 바람직하다.1) 붙띄 오류에

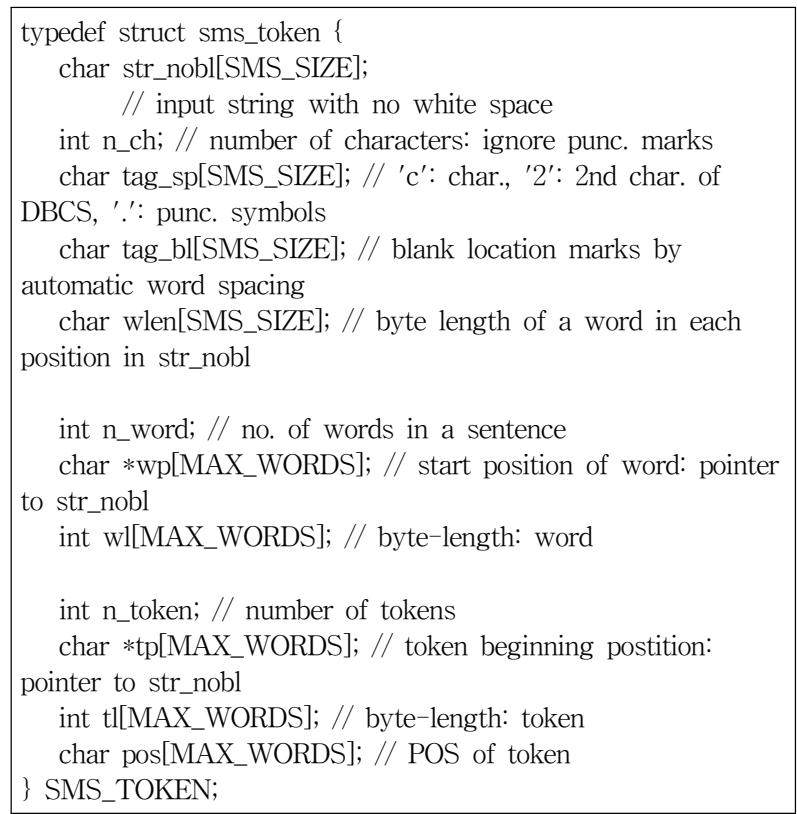

Fig. 3. Data structure for auto-spacing and tokens

의해 한 어절이 두 어절로 분리되는 부작용을 최소화하기 위한 전략으로 인하여 많은 복합명사들이 단위명사로 분리 되지 않게 된다. 따라서 자동 띄어쓰기를 적용한 후에 다시 복합명사 분해 모듈을 통해 복합명사를 분해하여 최종적으 로 문장을 복원하는 과정을 마무리한다[11]. 그 결과로부터 키워드들을 추출하고 추출된 키워드 중에서 스팸 어휘집에 등록된 키워드가 탐지되면 스팸 문자로 간주하게 된다.

이때, 스팸 어휘집에 등록된 어휘가 포함된 문자들을 모두 스팸으로 간주하는 것은 아니다. 예를 들어, "김대리, 오늘 회식은 회사 신용카드로 결제하세요”라는 문자 메시지에서 '대리', '카드' 때문에 스팸으로 간주하면 안 된다. 일반적으 로, 스팸 차단 시스템은 대량의 문자 발송 등 스팸이 의심스 러운 문자 메시지에 대해 스팸 차단 기능을 적용한다. 또한, white 리스트와 black 리스트를 반영하고 있으며, 특히 자신 의 주소록에 저장된 번호로 발신된 문자 메시지는 스팸으로 처리하지 않도록 하는 방법을 적용하여 false-positive 오류 (false alarm)를 최소화하는 방법을 사용한다[2].

\section{4. 실험 및 결과 분석}

변형된 SMS 문자열의 정규화 효용성을 실험하기 위하여 휴대전화를 통해 전송되는 문자 메시지에서 스팸 문자로 차

1) '띄붙 오류'는 '가고있다'와 같이 띄어써야 하는데 붙여쓴 오류이며 '붙뜨 오류'는 '검색시 스템'의 '시'와 '스' 사이와 같이 붙여야 하는데 띄어쓴 오 류이다. 띄붙 오류는 하나의 문자열에 2 개의 어절이 연결되어 그 의미를 파악하는데 어려움이 없으나, '붙띄 오류'는 한 어절이 2 개의 무의미한 어 절로 분리되어 그 의미가 훼손되는 문제점이 발생한다. 
단되는 문자 유형을 분석하였다. SMS 문자의 스팸 문자를 차단 방법은 크게 등록된 발신 번호와 회신 번호를 차단하 는 ‘번호 차단' 기법과 등록된 문구를 차단하는 '문구 차단' 방식으로 구분된다. '번호 차단' 방식과 '문구 차단' 방식은 다시 모든 사용자들에게 공통적으로 적용되는 것과 각 개인 이 등록한 것만 차단하는 것으로 구분된다.

실험 대상 문자는 $61,934,003$ 개이고 그 중에서 937,683 개가 스팸 문자로 분류되었다. 스팸으로 분류된 문자들을 '번호 차 단' 방식과 '문구 차단' 방식, 그리고 '공통 차단'과 '개인 차 단'으로 분류하면 표 1 과 같다. 일반 문구에서 차단되지 못한 스팸 문자 중에서 본 논문에서 제안한 SMS 문장의 정규화 기법을 적용함으로써 스팸으로 차단된 것은 137,221 개로 전 체 스팸 문자의 $14.6 \%$ 이다. 이는 SMS 문자열 정규화를 하 지 않았을 때 차단되는 스팸 문자 개수가 800,442 개인데 비 해 문자열 정규화를 통해 937,683 개로 증가하여 스팸 문자 차단 효과가 $17.1 \%$ 향상되는 효과가 있었다.

Table 1. SMS spam filtering result

\begin{tabular}{c|c|c|c}
\hline & $\begin{array}{c}\text { Number } \\
\text { Filtering }\end{array}$ & $\begin{array}{c}\text { Normal } \\
\text { Filtering }\end{array}$ & $\begin{array}{c}\text { Transformed } \\
\text { filtering }\end{array}$ \\
\hline Common & $\begin{array}{c}7.7 \% \\
(71,890)\end{array}$ & $\begin{array}{c}43.1 \% \\
(404,307)\end{array}$ & $\begin{array}{c}12.5 \% \\
(117,271)\end{array}$ \\
\hline Personal & $\begin{array}{c}19.0 \% \\
(178,160)\end{array}$ & $\begin{array}{c}15.6 \% \\
(146,105)\end{array}$ & $\begin{array}{c}2.1 \% \\
(19,950)\end{array}$ \\
\hline Total & $\begin{array}{c}26.7 \% \\
(250,040)\end{array}$ & $\begin{array}{c}58.7 \% \\
(550,412)\end{array}$ & $\begin{array}{c}14.6 \% \\
(137,221)\end{array}$ \\
\hline
\end{tabular}

\section{5. 결 론}

광고성 문자들은 문자 메시지가 자동으로 차단되는 것을 회피하기 위해 한글 문장을 다양한 형태로 변형하거나 왜곡 시키고 있다. 이러한 문자 메시지를 자동으로 차단하려면 변형되거나 왜곡된 문장들을 정상적인 한글 문장으로 정규 화해야 한다. 본 논문에서는 광고성 문자를 자동으로 인식 하여 차단하기 위해 변형된 문자열을 정상적인 문자열로 정 규화하는 방법을 제안하였다. 변형되거나 왜곡된 광고성 문 자 메시지를 정상적인 한글 문장으로 변환하여 정규화하고 정규화된 문장으로부터 자동 띄어쓰기 및 복합명사 분해 과 정을 거쳐 키워드를 추출하였으며, 이 방법을 적용하여 변 형된 문자열을 정규화함으로써 스팸 문자 차단 효과를 $17.1 \%$ 향상시키는 효과가 있었다.

\section{Reference}

[1] B. Y. Kim, A Study on the Morphological Characteristics of Communicative Languages by the Statistical Frequency, Master Thesis, Kookmin University, 2002.

[2] S. J. Lee and D. J. Choi, "Personalized mobile junk message filtering system," Journal of the Korea Contents Association, pp.122-135, 2011.

[3] S. S. Kang, "Junk-mail filtering by mail address validation and title-content weighting," Journal of the Korea Multimedia Society, Vol.9, No.2, pp.255-263, 2006.

[4] K. Tretyakov, "Machine learning techniques in spam filtering," Data Mining Problem-oriented Seminar, MTAT. 03. 177, pp.60-79, 2004.

[5] L. Zhang, J. Zhu, and T. Yao, "An evaluation of statistical spam filtering techniques," ACM Transactions on Asian Language Information Processing(TALIP), Vol.3, No.4, pp.243-269, 2004.

[6] C. Brutlag and J. Meek, "Challenges of the email domain for text classification," Proceedings of the 17th International Conference on Machine Learning, 2000.

[7] M. Sahami, S. Dumais, D. Heckerman, and E. Horvitz, "A Bayesian approach to filtering junk E-mail," Proceedings of the AAAI Workshop, pp.55-62, 1998.

[8] M. Salib, "MeatSlicer: Spam classification with Naive Bayes and smart heuristics," Proceedings of the Spam Conference, MA, Jan., 2003.

[9] K. Schneider, "A comparison of event models for Naive Bayes anti-spam E-mail filtering," Proceedings of 10th Conference of the European Chapter of the Association for Computational Linguistics(EACL 2003), pp.307-314, 2003.

[10] S. S. Kang and K. B. Hwang, "A language independent n-gram model for word segmentation," Proceedings of AI'2006, pp.557-565, 2006.

[11] S. S. Kang, "A decomposition algorithm of Korean compound nouns," Journal of KIISE(B), Vol.25, No.1, pp.172-182, 1998. 


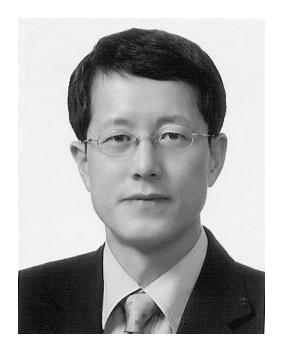

강 승 식

e-mail : sskang@kookmin.ac.kr

1986년 서울대학교 정보컴퓨터공학부

(학사)

1988년 서울대학교 컴퓨터공학과

(석사)

1993년 서울대학교 컴퓨터공학과(박사)

1994년 2001년 한성대학교 정보전산학부 교수

2001년 현 재 국민대학교 컴퓨터공학부 교수

관심분야 : 한국어정보처리, 자연어처리, 정보검색, 기계학습 